\title{
Aeration strategy for controlling grain storage based on simulation and on real data acquisition
}

\section{Daniela de Carvalho Lopes ${ }^{a, *}$, José Helvecio Martins ${ }^{a}$, Adílio Flauzino Lacerda Filho ${ }^{a}$, Evandro de Castro Melo ${ }^{a}$, Paulo Marcos de Barros Monteiro ${ }^{b}$, Daniel Marçal de Queiroz ${ }^{a}$}

\author{
a Federal University of Viçosa, Department of Agricultural Engineering, Avenue P.H. Rolfs, s/n, \\ Campus Universitário, Viçosa, 36570-000 MG, Brazil \\ ${ }^{\mathrm{b}}$ Federal University of Ouro Preto, Department of Control and Automation, Escola de Minas, \\ Campus Universitário, Morro do Cruzeiro, Ouro Preto, 35400-000 MG, Brazil
}

\section{A R T I C L E I N F O}

\section{Article history:}

Received 6 December 2007

Received in revised form

11 February 2008

Accepted 12 February 2008

\section{Keywords:}

Aeration

Control strategy

Simulation

Stored grain

Data acquisition

\begin{abstract}
A B S T R A C T
In this work a new control strategy for grain aeration systems was proposed. This strategy was implemented in a software package called AERO and relates four conditions which depend on real time data acquisition and on the process simulation. The main advantage of AERO controller is that it can be used in different geographic regions, during different seasons and with different aeration systems, automatically adjusting its set points. The objectives of AERO controller are to equalize the temperatures inside the bin, to cool the grain mass whenever is possible and to maintain the moisture content under safe conditions. The results showed that the proposed strategy is efficient to achieve these objectives. Moreover, significant energy saving has been achieved with the AERO controller.
\end{abstract}

() 2008 Elsevier B.V. All rights reserved.

\section{Introduction}

Aeration, the forced movement of ambient air through a grain bulk, is conducted to preserve or improve the physical conditions of the product. Actually, the use of this technique has been receiving more attention as a principal grain management tool since consumers, governments, processors and importers of grain are rejecting the use of residual chemicals on food grains. In spite of the shortage of sufficient cool air that may limit the usefulness of aeration in tropical and subtropical climates, its beneficial effects in these regions are also known. However, continued research is needed to optimize the use of aeration for preventing storage losses in the tropics (Navarro and Noyes, 2001).

An aeration system may perform inefficiently if the grain moisture or temperatures exceed the safe thresholds. Thus, a suitable combination of control parameters depends on the aeration system design and on the weather conditions of the region where it was installed. All organisms responsible for losses in stored grain and seed are affected by the temperature and moisture of the material. Such organisms include bacteria, insects, molds and mites. Therefore, cool and dry grain keeps longer if these deteriorating conditions are prevented or retarded (Talbot, 1999).

\footnotetext{
* Corresponding author. Tel.: +55 313138991930.

E-mail addresses: danielaclopes@gmail.com (D.d.C. Lopes), jhmartins@ufv.br (J.H. Martins), alacerda@ufv.br (A.F.L. Filho), evandro@ufv.br (E.d.C. Melo), paulo@em.ufop.br (P.M.d.B. Monteiro), queiroz@ufv.br (D.M.d. Queiroz). 0168-1699/\$ - see front matter @ 2008 Elsevier B.V. All rights reserved.
} doi:10.1016/j.compag.2008.02.002 
Stored-product insects are primarily thermophilic in nature. So, their growth and survivability is greatly influenced by temperature. The lower developmental threshold for most stored-product pests is approximately $18^{\circ} \mathrm{C}$ and the optimum developmental range of many stored grain insects is approximately $25-35^{\circ} \mathrm{C}$ (Ilelejia et al., 2007).

In dry and sound grain, the spores of the microflora on the grain are in a dormant state and remain inactive until conditions become favorable for their growth. Thus, microorganisms are unable to multiply when intergranular environment relative humidity is below 65\%, although it is generally accepted values up to $75 \%$ (Navarro and Noyes, 2001). For this, when discussing microflora activity and preservation of grain quality, it is more meaningful to consider the safe moisture content of the grain. This corresponds to a value up to which grain can be stored without danger of development of the microflora, varying according to the grain type.

Ideally, an efficient aeration controller should suit very different climatic conditions and storage situations throughout the world. For this, an interesting possibility is to develop a control strategy that combine the aeration process simulation with the real time data measures. With this strategy, control actions should be automatically adjusted according to different geographic regions and aeration systems, resulting in a site-specific controller into predictive aeration and storage modeling software.

Some authors have developed and validated mathematical models to predict mass and heat transfer in grain bins during the aeration process. These models have been used in order to estimate grain moisture content, temperature and dry matter loss, being interesting tools for more sophisticated control strategies and for optimizing monitoring procedures (Thorpe, 2001; Canchun et al., 2001; Devilla, 2002; Khatchatourian and Oliveira, 2006).

Software capable of simulating the aeration process provides other advantages as the possibility of using it to investigate the effects of the various parameters that affect the aeration process, considering storage bins of different sizes and made of different bin wall materials, filled with different grain types and located at different regions. Generally, conducting experiments to study these effects is expensive and a time-consuming process (Martins et al., 2001).

This work presents a new control strategy to manage grain aeration systems based on the process simulation and on real data acquisition. This controller was developed and tested at the Federal University of Viçosa (Brazil).

\section{Methodology}

The proposed strategy was implemented in a software package called AERO written in Delphi. This software is also capable of performing data acquisition, turning the aeration system on or off, simulating the aeration process according to user input data, saving monitoring and simulation results, beyond predicting important aeration parameters as the equilibrium and the aeration relative humidities. The AERO controller can be configured to maintain safe storage conditions with the maximum electrical energy saving (AERO_1) or to prioritize a more efficient grain bulk cool- ing (AERO_2). So, as long as grain temperature control is the primary objective of the storage manager, AERO_2 is recommended to control the fans. But for storage units for which costs restrictions are inevitable, AERO_1 is a better option.

The AERO_1 was used for monitoring and controlling an aeration system located at the Department of Agricultural Engineering of the Federal University of Viçosa (Brazil). The aeration system consisted of a corrugated cylindrical steel bin with a perforated floor, diameter of $2.6 \mathrm{~m}$ and grain mass depth of $2.0 \mathrm{~m}$. The aeration airflow used was equal to $0.0012 \mathrm{~m}^{3} \mathrm{~s}^{-1} \mathrm{~m}^{-3}$. The bin was filled with corn of $13.0 \%$ w.b. and the aeration system operated from June 2, 2005 to June 30, 2005 (late Autumn and Winter).

When the software was used to only simulate the system, results agreed very well with the experimental data. For this, considering the same period and the same system of the experimental trial, AERO_1 and AERO_2 effects on storage were simulated to compare their performances.

The one-dimensional mathematical model used to simulate the aeration process was proposed by Lopes et al. (2006) based on that formulated by Thorpe (1997) and presented in more detail by Thorpe (2001). With it it is possible to predict the distributions of temperature, moisture content and dry matter loss within the grain mass. During the experimental trial, this model was executed every $30 \mathrm{~min}$, when the control strategy was evaluated.

During simulation, the bulk of grain was divided into fifteen sections in the vertical direction. Then moisture contents, temperatures and dry matter losses within the grain mass were calculated after a time interval for each section in an iterative way. The fifteen sections used in the model corresponded to five times the real monitored levels inside the bin. Thus, during the experimental trial, each cable inside the grain bulk had three sensors. The use of more sections during simulation gives a better approximation of the continuous equations used by the mathematical model. Also, because of simulation is not the only module in the software and need to be frequently executed, there was the need of implementing a model as simple and uncluttered as possible without prejudice the correct solution procedure. For this reason, the proposed one-dimensional model was adopted.

The AERO control strategy was developed based on recommendations presented by Navarro and Noyes (2001), Lacerda Filho and Afonso (1992) and Martins et al. (2001). It aims to provide low and uniform temperatures inside the bin, maintaining the moisture content near to the safe value, with minimal energy input. For this, four conditions were established, relating the simulation results to real time data acquisition. According to these conditions the aeration system can be turned on, turned off or maintain its previous state.

So much for AERO_1 as for AERO_2, in the first condition (C1) if the dew point temperature of aeration air is smaller than the minimal grain temperature, the fan can be turned on. When this condition is satisfied the possibility of condensation in the grain bulk is minimized, assuring that any area inside the bin will receive air with favorable conditions for humidity accumulation (Lacerda Filho and Afonso, 1992). In AERO, the dew point temperature of the aeration air is calculated using the 
equation presented by Zolnier (1994):

$D_{P}=\frac{186.4905-237.3 \log _{10}(10 P)}{\log _{10}(10 P)-8.2859}$

where $D_{P}$ is the dew point temperature $\left({ }^{\circ} \mathrm{C}\right)$ and $P$ is the partial pressure of water vapour $\left(\mathrm{kP}_{\mathrm{a}}\right)$.

The objective of the second condition (C2) evaluated by AERO_1 and AERO_2 is to maintain the moisture content of dry grain at a safe level. This condition is based on the fact that the simulation results reflect the relationship between temperature and relative humidity inside the bin. So, depending on the aeration air conditions, grain absorbs, releases or maintains moisture. According to AERO, if the difference between the simulated grain moisture content and the safe one is smaller than 0.5 percentage points, the fan can be turned on. But, if at the begin of control, grain bulk presents average moisture content 0.5 percentage points greater or smaller than the safe value, then AERO controller will try to reach this value allowing aeration when air is drier or humid, respectively. Also, as ambient airflow rates are generally too low to significantly change grain moistures by more than 0.5 percentage points (Maier and Montross, 1997) only the moisture content of the grain section located near the air inlet is considered during the analysis of C2.

Two conditions (C3 and C4) are used to control the temperature inside the bin. Condition C3 is used to equalize the temperatures and condition $\mathrm{C} 4$ is used to cool the grain bulk. According to C3, AERO_1 and AERO_2 allow the fan to be turned on if a temperature difference greater than $5^{\circ} \mathrm{C}$ is observed inside the bin and if the simulated temperature difference is smaller than the real one. According to C4, AERO_2 rec-

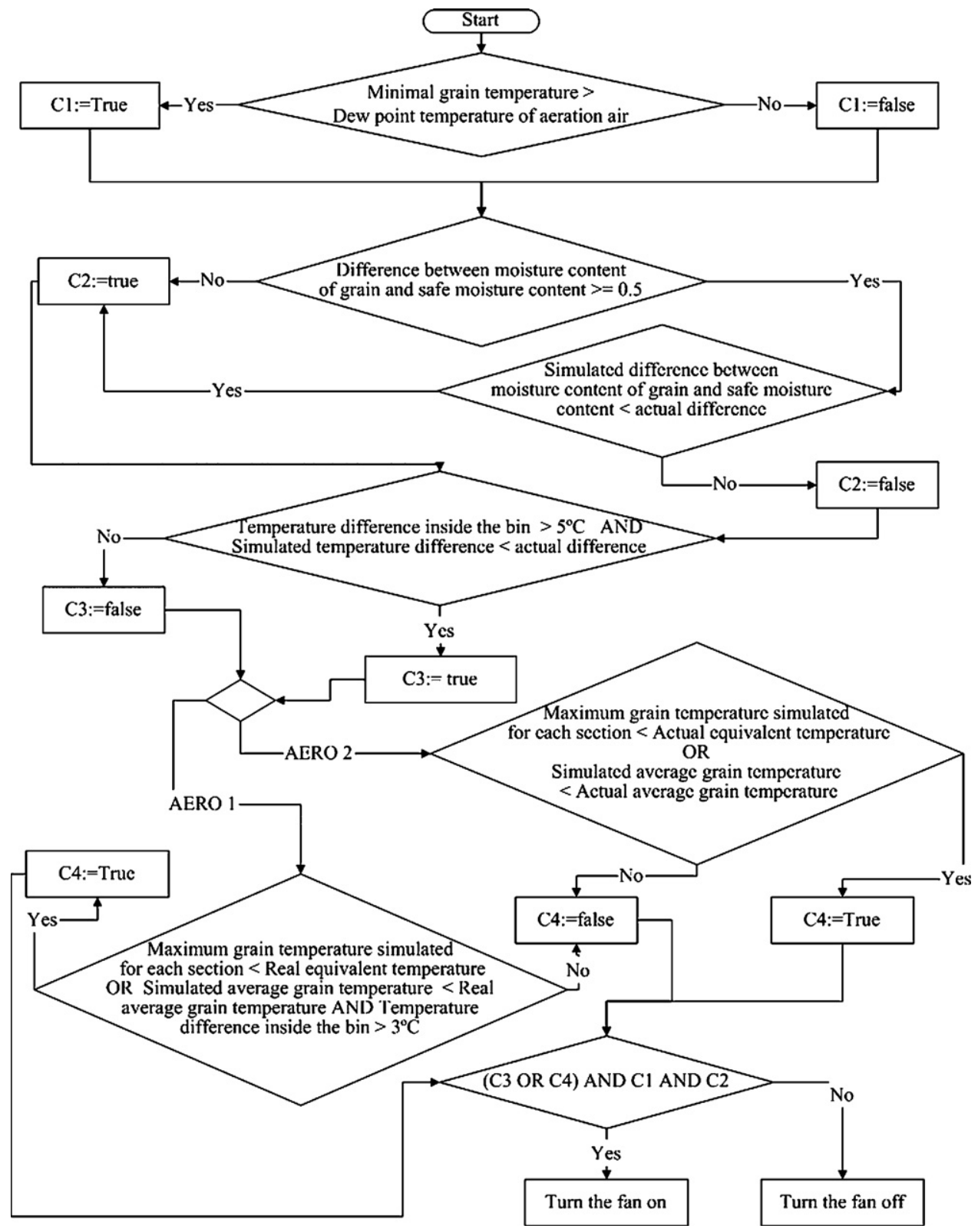

Fig. 1 - Algorithm of the AERO control strategy. 
ommends to turn the fan on if some one of the simulated temperatures for each grain section is smaller than the real one equivalent to it or if the simulated average grain temperature is smaller than the real one. When AERO_1 is used, the fan can be turned on if some one of the simulated temperatures for each grain section is smaller than the real one equivalent to it or if the simulated average grain temperature is smaller than the real one and if the temperature difference inside the bin is greater than $3^{\circ} \mathrm{C}$. This additional restriction limits the aeration hours and results in energy saving without prejudice the storage quality.

These conditions aim to ensure the safe storage mainly in tropical and subtropical regions, where grain cooling is usually insufficient to achieve complete insect control by itself. In these regions, the primary objective of the aeration should be to maintain the temperature difference smaller than $3^{\circ} \mathrm{C}$ inside the bin. But, in practice, values up to $5^{\circ} \mathrm{C}$ are acceptable (Navarro and Noyes, 2001; Martins et al., 2001). Fig. 1 presents the algorithm of the AERO control strategy.

When the control strategy is performed, the simulation time varies from 0.50 to $10 \mathrm{~h}$, depending on how near the grain temperature is to the ambient air temperature. Thus, it is larger as smaller is the difference between these two parameters. This procedure is followed because, when the grain temperature is near the aeration air one, the effects of aeration are slower. In this case, simulation considering a little interval of system operation is not capable of recognizing the real aeration air capacity for cooling or homogenizing the grain bulk. As the simulation is executed every $30 \mathrm{~min}$, the minimal time considered was $0.5 \mathrm{~h}$. Since, in tropical and subtropical climates, wide temperature fluctuations generally occur between day and night, the maximum simulation time limit of $10 \mathrm{~h}$ was adopted. Thus, if the absolute difference between the maximum grain temperature and the aeration air be smaller than one, the simulation time used for the model is $10 \mathrm{~h}$. But, if this difference be greater than twenty, the simulation time used is $0.5 \mathrm{~h}$. For differences inside this range the aeration time is calculated using Eq. (02). These simulations always are executed considering the fan turned on and every $30 \mathrm{~min}$ a new simulation is executed to evaluate if the relationship between ambient and grain conditions are modified.

$T=\frac{10}{\left|T_{m}-T_{a}\right|}$

where $\mathrm{T}$ is the simulation time $(\mathrm{h}), \mathrm{T}_{\mathrm{m}}$ is the maximum grain temperature $\left({ }^{\circ} \mathrm{C}\right)$ and $\mathrm{T}_{\mathrm{a}}$ is the temperature of the aeration air $\left({ }^{\circ} \mathrm{C}\right)$.

The data acquisition system used during the field trial was based on digital addressable devices, but other technologies can be used to perform the environmental measurements. Basically, the in-built equipment necessary to implement the strategy includes a temperature and relative humidity sensor for monitoring the ambient air conditions, temperature sensors located inside the grain bulk, a temperature sensor located at the plenum of the bin for monitoring the temperature of aeration air and an electronic switch (or similar equipment) to automatically turn the fan on or off. The number of sensors located inside the grain mass will depend on the dimensions of the structure and on the available budget. Many sensors will perform a better monitoring, but can increase the project costs. According to Silva et al. (2000), the maximum distance between cables (horizontal direction) should be $6.0 \mathrm{~m}$ and the maximum distance between sensors (vertical direction) should be $2.0 \mathrm{~m}$ to assure a reliable temperature monitoring.

\section{Results and discussion}

According to the results obtained in this study, the two AERO control options are effective for maintaining the temperature differences inside the storage structure under acceptable values, reducing grain temperatures to a level that slows the insect development and maintaining the estimated grain moisture contents under safe limits with electrical energy saving. Therefore, is important to study the effects of the strategy on the moisture content in more detail, relating the estimated values to the measured ones.

As the study was conducted in a small storage structure (15 t), the incident solar radiation in the bin wall significantly

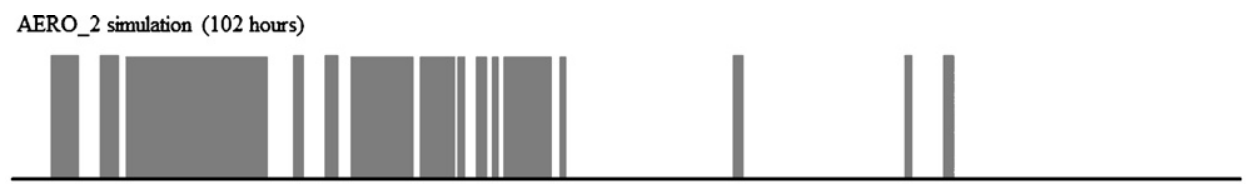

AERO_1 simulation (39 hours)
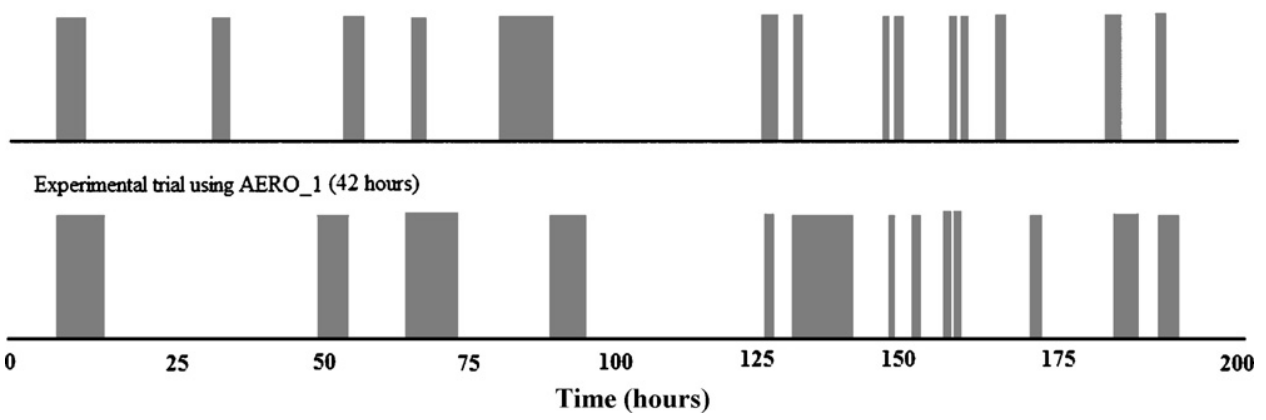

Fig. 2 - Moments when the fan was turned on during the experimental trial using AERO_1 compared to the simulated activations recommended by AERO_1 and AERO_2 for the same period. 
influenced the stored grain ecosystem, warming the grains located near the bin walls. Thus, even after grain bulk had reached lower and uniform temperatures, the aeration system was turned on for small periods, since sensors detected peripheral grain increases of temperature that could prejudice storage conditions. This fact is well represented by the math- ematical model that considers a small temperature rise inside the bin during the periods in which the fan is turned off.

Fig. 2 shows the moments when the fan was turned on during the experimental trial using AERO_1 compared to the simulated activations recommended by AERO_1 and AERO_2 for the same period. It is clear that the simulated data for
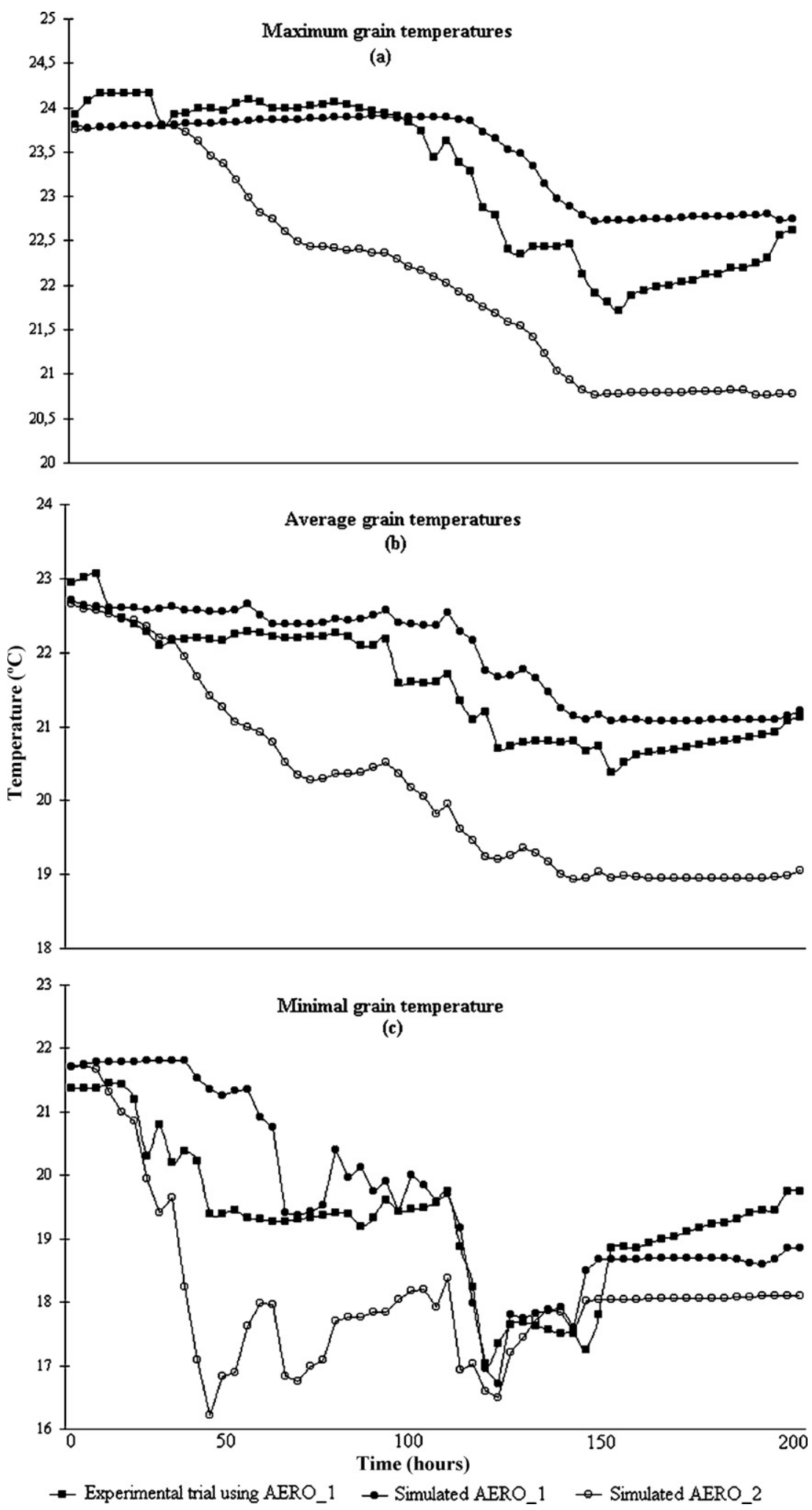

Fig. 3 - Grain temperatures changes during the experimental trial and simulations. 


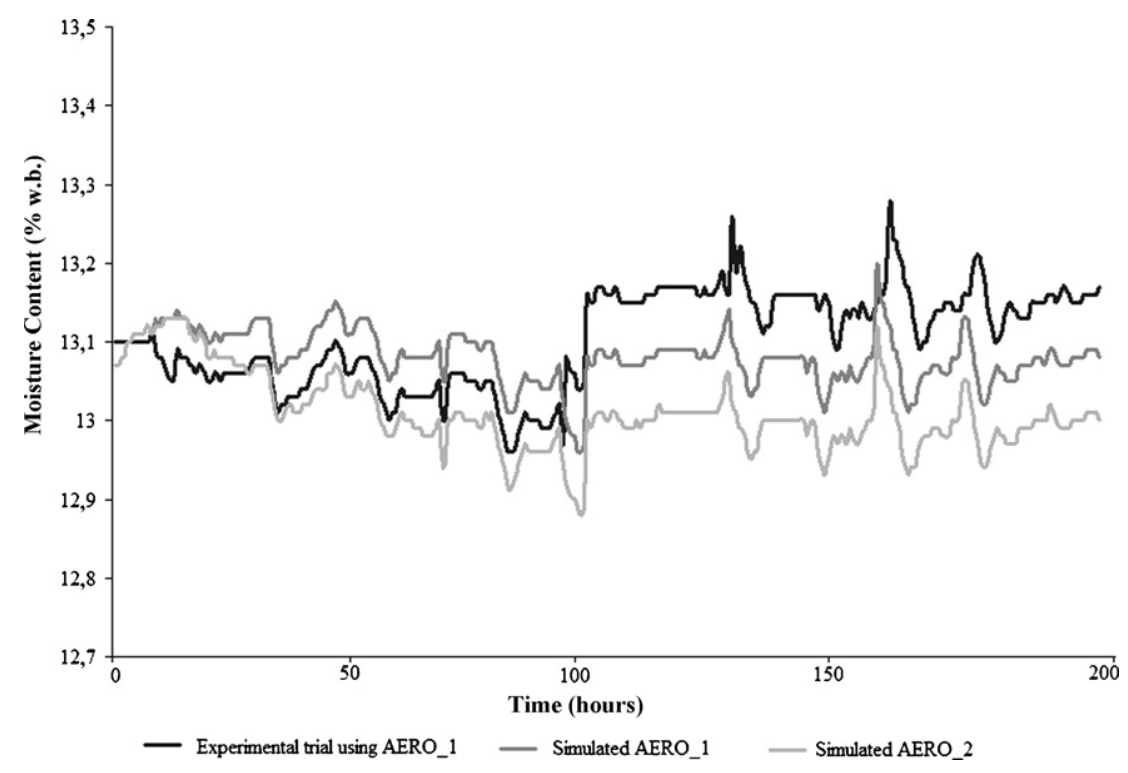

Fig. 4 - Estimated average moisture content changes during the experimental trial and simulations.

AERO_1 agreed very well with the experimental ones, which intensifies the model reliability. It also can be seen that the AERO_1 fan operated for half of the time of AERO_2 one and was turned on for small periods with large frequency. Since AERO_2 allows the fan to be turned on to cool the grain bulk when temperature difference is smaller than $3^{\circ} \mathrm{C}$, it operated for a longer period, but with smaller frequency.

The additional hours of continuous fan operation verified for AERO_2 resulted in a faster and more effective cooling, which was maintained until the study ended. These effects can be seen in Fig. 3(a)-(c). Initially, the temperature difference inside the bin was $2.0^{\circ} \mathrm{C}$. The average, maximum and minimum grain temperatures were $23.1,24.0$ and $21.7^{\circ} \mathrm{C}$. During this period the relative humidity of the ambient air varied between $37.5 \%$ and $98.4 \%$, with average of $83.2 \%$ and the temperature of the ambient air varied from 7.7 to $28.8^{\circ} \mathrm{C}$, with average of $16.4^{\circ} \mathrm{C}$. At the end of the studied period the temperature differences inside the bin were $3.5,3.0$ and $2.7^{\circ} \mathrm{C}$ for the field trial, the simulated AERO_1 and the simulated AERO_2, respectively. The increase in the temperature differences was acceptable, since they were within the required levels for safe storage and the studied control strategies yielded favorable temperatures for insect control. The maximum grain temperatures drop to $22.7,22.5$ and $20.8^{\circ} \mathrm{C}$ while the minimum temperatures reached $19.7,19.0$ and $18.1^{\circ} \mathrm{C}$ when considering the simulated AERO_1, the field trial and the simulated AERO_2, respectively. During the field trial the final average grain temperature was $21.1^{\circ} \mathrm{C}$. Also, the final average grain temperature obtained with simulated AERO_1 was $21.2^{\circ} \mathrm{C}$ and with simulated AERO_2 was $19.1^{\circ} \mathrm{C}$.

The average grain moistures changes, estimated during the experimental trial and the simulations, are illustrated in Fig. 4. The results obtained with the experimental trial and simulations were very similar. In all cases, the safe moisture content was successfully maintained nearly constant throughout the studied period. The maximum change in moisture content observed for the three possibilities was 0.2 percentage point.
In spite of requiring accurate sensors and a computer to monitoring and performing the control actions, the AERO controller automatically adjusts its settings according to different regions, seasons and aeration systems due to its capacity of simulating the aeration process and relating it to the real time data acquisition. Using AERO grain manager have only to configure the system structure when executing the software for the first time informing how many sensors are inside the bin, how many bins will be controlled and their dimensions, the aeration airflow for each bin and the stored-product in each bin. These advantages contrast with the characteristics of other controllers, which settings used for deciding when turn fans on or off depend on the weather of the region where the aeration system will operate. In other strategies, as ambient temperatures and relative humidities are usually variable with daily fluctuations and seasonal changes, the control settings can also widely vary in a same geographic region and for a same aeration system resulting in constant need of updating. Of course, the efficiency of ambient aeration strategies will depend on the availability of conditions capable of achieving aeration objectives, as cooling and equalizing grain temperatures. Under certain climatic conditions and in various geographic locations, ambient aeration cannot completely prevent the development of grain temperatures that are optima for stored-grain insects and fungi. In these situations, AERO can be combined with chilling aeration. Thus, refrigerated air may be used initially to cool the grain bulk and AERO may be used to maintain safe conditions along the storage period.

\section{Conclusions}

The results of this study indicated that efficient aeration can be achieved using the AERO control strategy. Based on the results obtained in this work, the AERO controller showed a significant potential for cooling and maintaining the grain 
bulk under levels that reduce insect and mold activities. In spite of this control strategy requires reliable equipment and software, it is powerful enough to meet the needs of optimum grain storage, electrical energy saving, data simulations and data saving. As the AERO controller evaluates the relationships between simulated and real data, it can be used in different regions, during different seasons and with different aeration systems, automatically adjusting its set points. Also, this control strategy can be easily adapted to different data acquisition systems, as it can be used to monitor and control several storage structures.

\section{R E F E R E N C E S}

Canchun, J., Da-Wen, S., Chongwen, C., 2001. Computer simulation of temperature changes in a wheat storage bin. J. Stored Prod. Res. 37, 165-177.

Devilla, I.A., 2002. Simulação de deterioração e de distribuição de temperatura e umidade em uma massa de grãos armazenados em silos com aeração. Universidade Federal de Viçosa, (Tese de Doutorado em Engenharia Agrícola), Brazil.

Ilelejia, K.E., Maier, D.E., Woloshukb, C.P., 2007. Evaluation of different temperature management strategies for suppression of Sitophilus zeamais (Motschulsky) in stored maize. J. Stored Prod. Res. 43 (4), 480-488.

Khatchatourian, O.A., Oliveira, F.A., 2006. Mathematical modelling of air flow and thermal state in large aerated grain storage. Biosyst. Eng. 95 (2), 159-169.
Lacerda Filho, A.F., Afonso, A.D.L., 1992. Algumas considerações sobre aeração de grãos agrícolas. Notas de aula. Universidade Federal de Viçosa. Brazil.

Lopes, D.C., Martins, J.H., Melo, E.C., Monteiro, P.M.B., 2006. Aeration simulation of stored grain under variable air conditions. Postharv. Biol. Technol. 42, 115-120.

Maier, D., Montross, M., 1997. Aeration technology for moisture management. Managing moisture in grains and oilseeds. In: Proceedings of the University of Illinois Grain Quality Conference, Illinois.

Martins, J.H., Mota, A.M., Fonseca, J.A., 2001. Simulation of an automatic controller for stored grain aeration systems. Engenharia na Agricultura 9 (1), 55-70.

Navarro, S., Noyes, R.T., 2001. The Mechanics and Physics of Modern Grain Aeration Management. CRC Press, Boca Raton.

Silva, J., Lacerda Filho, A. F., Devilla, I. A., 2000. Aeração de grãos. In: Silva, J. (Ed.), Secagem e armazenagem de produtos agrícolas. Editora Aprenda Fácil, pp. 261-277.

Talbot, M.T., 1999. Management of stored grains with aeration. In: Circular 1104. Agricultural and Biological Engineering Department, Florida Cooperative Extension Service, Institute of Food and Agricultural Sciences, University of Florida.

Thorpe, G.R., 1997. Modelling ecosystems in ventilated conical bottomed farm grain silos. Ecol. Modell. 94, 255-286.

Thorpe, G.R., 2001. Physical basis of aeration. In: Navarro, S., Noyes, R.T. (Eds.), The Mechanics and Physics of Modern Grain Aeration Management. CRC Press, Boca Raton, pp. 125-194.

Zolnier, S., 1994. Psicrometria I-caderno didático 13. Imprensa Universitária, Universidade Federal de Viçosa, Brazil. 